\title{
COVID-19 and Youth Sports: Psychological, Developmental, and Economic Impacts
}

\author{
Jimmy Sanderson and Katie Brown \\ Texas Tech University
}

\begin{abstract}
COVID-19 has dramatically altered and disrupted sport in unprecedented ways, and youth sports is one sector that has been profoundly impacted. In the United States, the youth sports industry generates $\$ 19$ billion dollars annually, while youth sport tourism is estimated at $\$ 9$ billion annually. With youth sports at a standstill, the effect on the youth sports infrastructure is significant. The purpose of this scholarly commentary was to discuss the psychological, developmental, and economic fallout from the stoppage of youth sports that has touched millions of participants, their families, and a substantial youth sports structural system. This work also addresses the potential restructuring of youth sport megacomplexes, cascading effects of canceled seasons, likely sponsorship losses, and potential growing socioeconomic divide in participation that could result from the pandemic. Thus, there is still much uncertainty about the future of youth sport participation and subsequent adjustments that may impact established participation and consumption norms.
\end{abstract}

Keywords: children and sports, family and sport, parents and sport, sports and crisis

The global pandemic stemming from the novel coronavirus disease 2019 (COVID-19) has drastically altered sport in unprecedented ways. While every segment of the sport industry has been impacted, in terms of breadth, the youth sports sector is arguably the most significantly affected. For instance, estimates suggest that 45 million children play sports in the United States (Swanson, n.d.). These figures, coupled with estimates of approximately 7.9 million teens participating in high school sports in the United States (NFHS News, 2019), illustrate how the reduction in sport participation has touched millions of participants. Moreover, there is a comprehensive ecosystem underpinning the youth sports industry that also has been significantly disrupted and affected, stemming from the cancellation of youth sports (Bachman, 2020). In the United States, the youth sports industry is a $\$ 19$ billion market annually (Rishe, 2020), and the annual tourism impact from youth sports is estimated at $\$ 9$ billion (Popke, 2017). With youth sports being at a standstill for approximately 2 months, many youth sport

The authors are with the Dept. of Kinesiology and Sport Management, Texas Tech University, Lubbock, TX, USA. Sanderson (jimmy.sanderson@ttu.edu) is corresponding author. 
organizations and municipalities have sustained significant financial loss. Thus, several notable youth sport organizations, such as the National Council of Youth Sports and travel tournament organizer Triple Crown Sports, are spearheading efforts to seek $\$ 8.5$ billion dollars in relief from the U.S. Congress to offset season and tournament cancellations (Solomon, 2020).

While COVID-19 has harmed the entire sports industry, the impact is particularly acute for youth sports, given the sheer volume of participants and the attending substructure that funds this market. In this commentary, we discussed the psychological, developmental, and economic fallout from an unprecedented stoppage in sports that has affected millions of participants. We acknowledge that each of these three areas are interrelated, and yet we believe they also warrant discussion individually. Therefore, we explored each of these areas separately and then concluded with a discussion of how they work together and may influence a "new normal" of youth sports in the United States. We also recognize that society is continually evolving and adapting as a result of COVID-19. Thus, there is still uncertainty about the future of sport participation and adjustments that may impact established youth sport participation and consumption norms.

\section{Psychological Impacts}

For many families in the United States, sport is a prominent, if not predominant, activity (Dunn, Dorsch, King, \& Rothlisberger, 2016; Mirehie, Gibson, Kang, \& Bell, 2019; Stefansen, Smette, \& Strandbu, 2018). Indeed, Bremer (2012) suggested that, for many families in Western culture, participation in youth sports is "a way of life" (p. 245). For some families, sport also is a central component of their identity (Boneau, Richardson, \& McGlynn, 2020), as many families make financial and social sacrifices so their children can participate in sports (Dorsch, Smith, \& McDonough, 2009). With the respite from youth sports, a primary activity for families has been suspended, necessitating adjustments to the family routine. Sport being at the epicenter of the family schedule is largely a function of parental investment (Dorsch et al., 2009; Turman, 2007), which often derives from parents seeking identity fulfillment from their children's athletic performance (Meân \& Kassing, 2008).

For example, for many families, sports drives the family calendar. Meals, travel plans, vacations, and other activities are prioritized around the sports schedule. With the growth of youth sports, many children now practice daily or multiple times a week, which can make family time in the evenings minimal. For some families, although these schedules can be hectic and challenging, it is a sacrifice they are willing to make, and time is marked according to the sports schedule. With the societal adjustments introduced by COVID-19, this normally structured and rigid schedule has been abruptly freed. With organized team activities and games paused, some parents may be struggling to cope with their children being unable to participate in athletics (Butler, 2020). For instance, the first author's son plays high school baseball, and the first author has struggled with the cancellation of the high school baseball season, as he greatly enjoys watching his son participate. In conversations with other parents, the first author has been told that for many parents, "baseball is life," and the adjustment to "no baseball" 
has been challenging. Indeed, many families are accustomed to devoting significant time to their children's sporting activities (Mirehie et al., 2019), and with events suspended, these parents and children may find this void challenging. For example, consider some parents who report that they prioritize sports over anything else (Dorsch et al., 2009). Amidst the pandemic, these parents may struggle navigating this uncertain time, as prioritizing youth sports has been firmly ensconced as the hierarchical activity in families' schedules and lifestyles (Trussell, 2009).

Additionally, for many parents, monetary investments in their children's athletic participation is viewed as a necessary expenditure to provide their children with every opportunity to attain their athletic potential (Hyman, 2009), a commitment that can be a heavy financial burden (Wiersma \& Fifer, 2008). Nevertheless, despite these challenges, some parents are more than willing to make financial sacrifices, particularly if they perceive such spending to be necessary for their child to obtain a college scholarship (Witt \& Dangi, 2018). However, with COVID-19 impacting many people economically, the financial burden associated with youth sports may now be too great to bear for some families. Consequently, some parents may experience guilt, if they no longer have the discretionary income to pay for competitive travel tournaments and private lessons, for instance. Moreover, some children also may experience these feelings if they ask their parents to pay for sporting activities, when parents may be struggling to make the mortgage/rent payments, utilities, and provide food. These feelings are likely to be difficult to process, particularly as parents/children see others who are still able to provide these opportunities.

For many parents, their behavior and decision-making in youth sports is correlated with the desire for their child to obtain a college scholarship (Carpenter, 2019; Witt \& Dangi, 2018). With the disruptions associated with COVID-19, stress also may accumulate for parents and children because the college recruiting cycle has been disrupted. For instance, most college programs have postponed or canceled summer camps, and many travel tournaments have also made similar decisions. Thus, for some student-athletes, such as those in their sophomore and junior seasons, they are missing out on what has historically been a prime recruiting season, and the uncertainty about how to be seen by coaches and the absence of showcases and other competitive events may aggravate these feelings.

The drive for a college scholarship situates the centrality of athletic identity for some youth athletes. Accordingly, attending to the identity consequences for these athletes stemming from the loss of their sports seasons is also crucial to understand. For many individuals, being an athlete is central to their identity. Consequently, when athletes retire or transition out of sport, this process can be fraught with challenges (Menke \& Germany, 2019; Stokowski, Paule-Koba, \& Kaunert, 2019). Indeed, for many athletes, sport has been a core activity in which they have participated since childhood, and navigating life without athletic participation often elicits stress and other mental and psychological health effects (Giannone, Haney, Kealy, \& Ogrodniczuk, 2017; Jewett, Kerr, \& Tamminen, 2019). Given the complexities associated with leaving sport quite abruptly amidst the pandemic, many young athletes are plausibly feeling stress and, perhaps, even grief (Cassilo \& Sanderson, 2019). While many youth sport participants will presumably play again, for some athletes, their athletic careers have hastily ended. 
For instance, consider senior high school athletes who lost their spring sport seasons. Although some of these individuals may be able to play in college (although there is uncertainty here, as well), many of these athletes have seen their athletic careers come to an unfulfilling conclusion. Whereas the emotional toll here is significant, missing out on the rituals associated with being a senior high school athletic participant (e.g., senior nights at final home games) enhances the loss. Amidst the pandemic, some efforts have been made to compensate for these rituals. For example, ESPN anchor Scott Van Pelt encouraged people to send pictures and videos of senior athletes in college and high school, using the hashtag \#SeniorNight (Russell, 2020). Van Pelt featured submission across both social media and on SportsCenter (Zielonka, 2020), giving some semblance of normalcy to the senior athletes who were featured.

\section{Developmental Impacts}

Children who participate in sport face varying levels of time demands, which in theory, are designed to help them practice and improve in their sport. For example, in community-based recreation leagues, children often practice once or twice a week. For those who participate in high school and/or competitive club/travel teams, practice often occurs daily, with games scheduled throughout the week and throughout the weekend. Practice and training in organized youth sport, such as community-based recreation leagues and some interscholastic competitions, allow young athletes to develop their skills. However, with COVID-19 and its attending restrictions, athlete development will be an important outcome to monitor. Indeed, with the cancellation of the spring athletic seasons, children in a number of sports have lost developmental opportunities via formal, structured workouts. Certainly, these restrictions do not preclude any child from practicing on his/her own, and/or with parent supervision. However, with the economic hardships many families are facing as a result of COVID-19, these families may not be able to provide such opportunities for their children due to other obligations. Accordingly, the disruption of youth sports may further divide class groups in youth sports (Mirehie et al., 2019). Money and time are key factors in parents being able to provide for their children's athletic participation (Holt, Kingsley, Tink, \& Scherer, 2011), and the pandemic impacts the quality and quantity of time and economic resources parents can provide. For example, with baseball, some families have batting cages on their property, and this resource provides their child with an advantage, whereas other children who may have been able to use batting cages at community facilities are no longer able to do so. As an additional illustrative case, Butler (2020) chronicled the story of a California family who decided to temporarily relocate to Oklahoma to live with family members so their daughter and her friend could participate in softball. Certainly, the ability to pack up and move halfway across the country is a luxury afforded to very few families.

For instance, some parents may still be able to continue paying for a private coach to tutor their children or have employment that allows them to spend time helping their children practice. Yet, other parents may have to find new or additional employment to offset the financial impact of the pandemic, and therefore, time and money for these families may be in short supply. Consequently, children 
who are unable to consistently practice may experience adverse effects once sport participation resumes. Additionally, many high school coaches and other youth sport coaches have posted virtual workouts via YouTube and are utilizing other technology to help athletes maintain physical conditioning and skill development while isolated. These efforts are certainly commendable, but there is no guarantee that athletes are using them or completing the workouts in the manner that the coach intends. These efforts also are dependent on reliable Internet access, which not all families can afford. Moreover, some children may be able to access these videos through school-sponsored tablets, but these devices will have to be returned when the school year closes. Thus, these children may no longer be able to access digital workouts and training.

Accordingly, when youth sport teams are able to come back together, the effects of the layoff on development will be important to observe. Will there be a marked difference with those who have consistently worked out? If so, what will the impact be? It seems plausible that children who maintained workouts may see the majority of playing time, which may affect those who were not able to practice consistently, potentially increasing their probability for dropout. An additional outcome to observe is the impact on multisport participation. For instance, if high school sport schedules are moved back and sports such as volleyball and softball occur in competing, as opposed to complementary, seasons, some sports may see lower participation rates, and young athletes may be increasingly forced to specialize in one sport. Additionally, some smaller high schools are dependent on multisport athletes to field their athletic teams. Thus, merging historically contrasting seasons may necessitate that some schools reduce the athletic teams they can field.

\section{Economic Impacts}

As social distancing measures have been extended, many youth sport organizations have undergone stress regarding financial loss and will likely seek to recoup revenue in the summer. Youth sport tournaments attract visitors from all over the country, generating revenue for the facility, hospitality industry, and retailers. The operation of sport facilities for youth travel teams is a growing industry, as young athletes often specialize in specific sports and utilize travel teams to gain exposure for potential scholarships (Broughton, 2019). Travel teams bring in millions of dollars to local economies each year, as sport tourists (parents, children, fans) spend money at the facility, local hotels, restaurants, and retail shops. A decline in revenue is an immediate economic impact resulting from the pandemic, but there are also cascading effects that could affect the youth sports industry. Even in the event that summer sports are allowed to resume, many families may suddenly find themselves unable to continue financially supporting their child in a sport. The economic impacts of COVID-19 may reverberate for more than just a season, as it is a multifaceted issue that youth sport organizers must now face in unprecedented times. The following section examines the potential economic impacts of COVID-19 as it pertains to athlete participation, local athletic facilities, and the affiliated economy.

Participation in team sports dropped from $45 \%$ in 2008 to $38 \%$ in 2014 following the 2008 recession (Fernandez \& Julian, 2020). The economy eventually recovered, but participation remained at postrecession levels. According to 
multiple studies, family income continues to be a deciding factor in the decline of youth sport participation (LaFerney, 2016). The socioeconomic divide between families could increase following the global pandemic, as currently, only $28 \%$ of teenagers from low-income families (less than $\$ 25,000$ ) participate in team sports, and $46 \%$ from the same age group come from households that make more than $\$ 100,000$ (LaFerney, 2016). With stay-at-home orders in effect, millions of people have seen reduced hours and been furloughed or laid off from their jobs. Many have had to choose between feeding their children or paying rent, so it stands to reason that following the reopening of the economy, team-sport participation could see a decline in those who can afford to play.

In spite of the stagnation of participation, the building or upgrading of youth sports facilities has proved to be a booming business. More than $\$ 550$ million has been spent on developing youth sport facilities designed to host tournaments over the past 3 years (Broughton, 2019). In previous years, youth sport tourism has had a major financial impact. For example, in Vicksburg, Mississippi, the Sports Force Parks facility hosted over 1,800 tournament teams and attracted 175,000 visitors in 2019. Hotel rentals associated with the tournaments were estimated to be at 25,000 rooms a night, with a total economic impact of \$24 million (Gillette, 2019). The Grand Park Sports Campus in Westfield, Indiana, home to 400 acres of land, baseball fields, and indoor facilities, could lose $\$ 85$ million that would have been spent at the complex and surrounding area if parks continue to stay shut down (Christian, 2020). Many youth sport complexes are still attempting to hold tournaments for later in the summer, such as Ford Park in Beaumont, Texas, which has reduced entry fees to this year's U.S. Fastpitch Association (USFA) Western Nationals in order to entice participants. However, this year, fans are not allowed to attend the event, which will further reduce the revenue the complex will bring in should teams decide to participate.

Youth sport facilities bring in revenue not only for the complex, but for the surrounding economy. The ripple effect of the global pandemic is hitting local economies, including small businesses that serve as sponsors, restaurants, and hotel chains. Projected losses as a result of the pandemic could be devastating, and a loss in foot traffic may inevitably lead to a reduction of money put into the local economy. This can cause negative effects where youth sport facilities, local businesses, and families are each individually impacted, which then potentially compounds each other. For example, countless sponsors for youth sport teams are local small businesses, as it provides marketing, philanthropy and visibility opportunities, potential returns on investment, and a way to give back to the community. In youth sports, sponsorships help keep player participation fees low for families, as well as assist in various other expenses (National Alliance for Youth Sports, 2015). Small business owners have been significantly impacted by the pandemic, and even though states are reopening, the guidelines put in place still represent significant hurdles to revenue generation. Local small businesses will have to operate at decreased capacity and have increased costs in order to comply with safety and sanitation standards, and many employees may not feel safe returning to work yet (Stankiewicz, 2020). If previous or potential sponsors are unable to offer financial assistance for teams, player participation fees will inevitably rise, thus conceivably decreasing the number of families that are able to afford to take part. 
Following the pandemic, the youth sports facility industry may have to reexamine the financial structure of megacomplexes. As much of the revenue is not evenly distributed throughout the year, many complexes could struggle to survive due to the pandemic (Solomon, 2020). The megacomplexes that depend on significant municipality support will likely face budget cuts, as the local economies have suffered as a result of COVID-19. However, youth sport has rebounded after a crisis before (albeit, following a national recession and not global pandemic), so many tournament organizers are hoping that, once again, the industry will recover and young athletes will be able to move their athletic careers forward soon.

\section{Implications and Conclusion}

COVID-19 has generated uncertainty in the future of youth sports and created psychological, developmental, and economic fallouts from the stoppage of sports. While examined individually to provide a complete picture of the effects of the pandemic, it is impossible for these areas to exist completely independently of each other. Young athletes are struggling with lost playing seasons and their athletic identity, and communities, organizations, and families are grappling to remain financially stable. Parents also may no longer be able to provide opportunities for their children to participate in competitive travel sports. The loss of these opportunities is likely to bring some psychological struggles, as children are no longer able to participate in activities that they are accustomed to, along with seeing friends and peers continuing to participate. Consequently, it is important for parents and others to look for ways to help these athletes come to terms with the end of their sports career and give them opportunities to express their feelings and to receive camaraderie and support. It also will be important for parents to have support for the changes that COVID-19 is likely to effect on youth sports. For example, some parents may no longer be able to make the financial sacrifices they have in the past so their children can participate in certain aspects of youth sports, and that can be a difficult conclusion to process, particularly for parents who are heavily identified with their children's sporting activities or who view sports as a gateway to a college scholarship. Parent support groups, whether physical or virtual, may be a way to help parents cope with some of the attending changes to youth sports arising from the pandemic. Such realities have led some to suggest that a unique opportunity exists to "re-imagine" youth sports (O'Sullivan, 2020).

Accordingly, while it is impossible to forecast the future, we offer some suggestions of what youth sports may look like going forward. First, it may be that many families reevaluate where sports fits in the family hierarchy. Some families may step back from the hurried schedules that accompany competitive youth sports and focus more on community and recreation-based sports leagues, as the costs here are likely to remain somewhat affordable and reduce the need to excessively travel. In addition, some parents may realize that they have placed too much emphasis on sports and find other activities to complement athletic participation that might result in more healthy and robust interpersonal and family relationships. Second, it is likely that the economic divide is likely to increase, as those families with higher socioeconomic status are likely to continue to provide opportunities 
for competitive travel sport, private coaching, and showcases. Consider the story of the California family temporarily relocating to Oklahoma so their daughter and her friend can play softball. Clearly, such opportunities are available to select few families. Third, the impact on development remains uncertain, but it seems that the economic divide may dictate how young athletes enhance their skills, subsequently influencing what kind of opportunities athletes have as they mature into high school and college. It may be that those children whose parents who are able to continue to afford the expensive things, like private instruction and travel teams, will have more opportunities to play in high school. It remains to be seen how such a reality might increase the already growing numbers of children dropping out of sports, but it may be that we see youth sport become a domain for the economically advantaged, thereby continuing to push out those in lower socioeconomic groups. We note that development also is likely influenced by federal, state, and local government policy making. Each state has handled the COVID-19 differently, with some states releasing restrictions sooner than others. This decision making could impact things like how many sports a high school or community recreation league is able to offer and push more sports to be offered in competing, as opposed to complementary, calendar seasons.

Many are wondering when the United States, and sports, will get back to business as usual. There may not be a return to the normal we knew, as we must adapt to the changing times surrounding us. Following major crises (e.g., September 11, 2001), the United States has established a new normal and persevered. As of this writing (May 2020), some states have created sports task forces to make guidelines for restarting youth sports (Frye, 2020). For instance, Ohio will allow baseball to resume in June, with regular temperature checks, masks for indoor training and in dugouts, travel history screenings, and checking to ensure players have not been exposed to anyone who has tested positive for COVID-19 (Tufaro, 2020). High-fives and hugs will not be allowed, which are inherently part of the celebratory moments in games. This new normal for Ohio youth sports may include limited fan access to practices and games, and less physical contact between players. Youth sport administrators will no doubt observe Ohio closely to develop their own plans and mitigate any potential risks Ohio assumes by being one of the first states to reopen. Youth sports may not look the same as it was before COVID-19, but hopefully, with extensive planning and creative solutions addressing the issues discussed herein, the future will look bright for young athletes.

\section{References}

Bachman, R. (2020, April 7). Coronavirus could cause youth sports recession. Retrieved from https://www.wsj.com/articles/coronavirus-could-cause-youth-sports-recession11586260815

Boneau, R.D., Richardson, B.K., \& McGlynn, J. (2020). "We are a football family": Making sense of parents' decision to allow their children to play tackle football. Communication \& Sport, 8(1), 26-49. doi:10.1177/2167479518816104

Bremer, K.L. (2012). Parental involvement, pressure and support in youth sport: A narrative literature review. Journal of Family Theory \& Review, 4(3), 235-248. doi:10.1111/j. 1756-2589.2012.00129.x 
Broughton, D. (2019, June 24). Construction of youth sport complexes continues at rapid pace. Retrieved from https://www.sportsbusinessdaily.com/Journal/Issues/2019/06/ 24/In-Depth/Youth-sports-complexes.aspx

Butler, T. (2020, May 21). California family leaves Oklahoma so their daughter and her friend can play softball. Retrieved from https://ktul.com/news/local/california-familyleaves-for-oklahoma-so-their-daughter-and-her-friend-can-play-softball

Carpenter, J. (2019, April 21). Parents can invest for years in kids' sports, but scholarships are elusive. Retrieved from https://www.wsj.com/articles/parents-can-invest-for-yearsin-kids-sports-but-scholarships-are-elusive-11555848000

Cassilo, D., \& Sanderson, J. (2019). From social isolation to becoming an advocate: Exploring athletes' grief discourse about lived concussion experiences in online forums. Communication \& Sport, 7(5), 678-696. doi:10.1177/2167479518790039

Christian, K. (2020, April 23). Area business could take $\$ 85 \mathrm{M}$ blow from Grand Park closure. Retrieved from https://www.ibj.com/articles/hamilton-county-businessescould-take-85m-blow-from-grand-park-closure

Dorsch, T.E., Smith, A.L., \& McDonough, M.H. (2009). Parents' perceptions of child-toparent socialization in organized youth sport. Sport, Exercise, and Performance Psychology, 4(1), 3-18. doi:10.1037/spy0000021

Dunn, C.R., Dorsch, T.E., King, M.Q., \& Rothlisberger, K.J. (2016). The impact of family financial investment on perceived parent pressure and child enjoyment and commitment in organized youth sport. Family Relations, 65(2), 287-299. doi:10.1111/fare.12193

Fernandez, G., \& Julian, A. (2020, March 9). Coronavirus updates: How the virus is affecting sports in the United States, around the word. Retrieved from https://www. cbssports.com/general/news/coronavirus-updates-how-the-virus-is-affecting-sportsin-the-united-states- around-the-world/

Frye, C. (2020, May 18). Ohio youth summer sports return, other sports remain sidelined due to pandemic. Retrieved from https://www.cleveland19.com/2020/05/18/despitepandemic-ohio-youth-summer-sports-are-back-other-sports-still-sidelines/

Giannone, Z.A., Haney, C.J., Kealy, D., \& Ogrodniczuk, J.S. (2017). Athletic identity and psychiatric symptoms following retirement from sports. International Journal of Social Psychiatry, 63(7), 598-601. PubMed ID: 28795636 doi:10.1177/ 0020764017724184

Gillette, B. (2019, July 11). Youth sport tourism a home run when it comes to economic impact. Retrieved from https://msbusiness.com/2019/07/youth-sports-tourism-a-homerun-When-it-comes-to-economic-impact/

Holt, N.L., Kingsley, B.C., Tink, L.N., \& Scherer, J. (2011). Benefits and challenges associated with sport participation by children and parents from low-income families. Psychology of Sport and Exercise, 12(5), 490-499. doi:10.1016/j.psychsport.2011.05.007

Hyman, M. (2009). Until it hurts; America's obsession with youth sports and how it harms our kids. Boston, MA: Beacon Press.

Jewett, R., Kerr, G., \& Tamminen, K. (2019). University sport retirement and athlete mental health: A narrative analysis. Qualitative Research in Sport, Exercise, and Health, 11(3), 416-433. doi:10.1080/2159676X.2018.1506497

LaFerney, D. (2016, June 21). Most youth sports have seen decline in participation since 2008, and cost plays a part. Retrieved from https://www.dallasnews.com/news/2016/ 06/21/most-youth-sports-have-seen-decline-in-participation-since-2008-and-cost-playsa-part

Meân, L.J., \& Kassing, JW. (2008). Identities at youth sporting events: A critical discourse analysis. International Journal of Sport Communication, 1(1), 42-66. doi:10.1123/ ijsc.1.1.42

Menke, D.J., \& Germany, M.L. (2019). Reconstructing athlete identity: College athletes and sport retirement. Journal of Loss and Trauma, 24(1), 17-30. doi:10.1080/15325024. 2018.1522475 
Mirehie, M., Gibson, H., Kang, S., \& Bell, J. (2019). Parental insights from three elite-level youth sports: Implications for family life. World Leisure Journal, 61(2), 98-112. doi:10.1080/16078055.2018.1550437

National Alliance for Youth Sports. (2015, January 1). 6 reasons why businesses should sponsor youth sports. Retrieved from https://www.nays.org/blog/6-reasons-whybusinesses-should-sponsor-youth-sports/

NFHS News (2019, September 5). Participation in high school sport registers first decline in 30 years. Retrieved from https://www.nfhs.org/articles/participation-in-high-schoolsports-registers-first-decline-in-30-years/

O'Sullivan, J. (2020, April 14). Reimagining youth sports in a post-COVID-19 world. Retrieved from https://changingthegameproject.com/reimagining-youth-sports-in-apost-covid-19-world/

Popke, M. (2017, September 6). Youth sports tourism boom generating mass media coverage-complete with added security. Retrieved from https://www.sports destinations.com/management/marketing-sponsorships/youth-sports-tourism-boomgenerating-mass-media-co-13416

Rishe, P. (2020, March 17). Coronavirus cancellations are impacting youth sports and fans' ability to release emotions at games. Retrieved from https://www.forbes.com/sites/prishe/2020/ 03/17/adverse-financial-impacts-upon-youth-sports-tourism-and-lost-psychic-incomethe-two-most-overlooked-aspects-of-sports-industry-disruptions/\#39ac60ce56cb

Russell, J. (2020, March 13). ESPN's Scott Van Pelt wants to recognize student-athletes whose seasons were cut short. Retrieved from https://www.washingtonpost.com/ sports/2020/03/a13/espns-scott-van-pelt-wants-recognize-student-athletes-whoseseasons-were-cut-short/

Solomon, J. (2020, April 10). Youth sports organizations propose $\$ 8.5$ billion COVID-19 federal relief fund. Retrieved from https://www.aspenprojectplay.org/coronavirus-andyouth-sports/reports/2020/4/10/youth-sports-organizations-propose-85-billion-covid19-federal- relief-fund

Stankiewicz, K. (2020, May 1). Mark Cuban: Texas reopening 'more show than go,' small business needs more help to do it safely. Retrieved from https://www.cnbc.com/2020/ 05/01/mark-cuban-small-businesses-in-texas-need-more-help-to-reopen-safely.html

Stefansen, K., Smette, I., \& Strandbu, A. (2018). Understanding the increase in parents' involvement in organized youth sports. Sport, Education and Society, 23(2), 162-172. doi:10.1080/13573322.2016.1150834

Stokowski, S., Paule-Koba, A.L., \& Kaunert, C. (2019). Former college athletes' perceptions of adapting to transition. Journal of Issues in Intercollegiate Athletics, 12, 403-426.

Swanson, B. (n.d.). Youth sport participation by the numbers. Retrieved from https:// www.activekids.com/football/articles/youth-sports-participation-by-the-numbers

Trussel, D.E. (2009). Organized youth sport, parenthood ideologies, and gender relations: Parent's and children's experiences and the construction of the "team family" (Unpublished doctoral dissertation). University of Waterloo: Waterloo, Ontario.

Tufaro, G. (2020, May 17). Ohio's resumption of youth baseball may provide template for New Jersey. Retrieved from https://www.mycentraljersey.com/story/sports/highschool/baseball/2020/05/16/ohios-resumption-youth-baseball-may-provide-templatenew-jersey/5207550002/

Turman, P.D. (2007). Parental sport involvement: Parental influence to encourage young athlete continued sport participation. Journal of Family Communication, 7(3), 151175. doi:10.1080/15267430701221602

Wiersma, L.D., \& Fifer, A.M. (2008). "The schedule has been tough but we think it's worth it": The joys, challenges, and recommendations of youth sports parents. Journal of Leisure Research, 40(4), 505-530. doi:10.1080/00222216.2008.11950150 
Witt, P.A., \& Dangi, T.B. (2018). Why children/youth drop out of sports. Journal of Park and Recreation Administration, 36(3), 191-199. doi:10.18666/JPRA-2018-V36-I3-8618

Zielonka, A. (2020, April 2). Scott Van Pelt on the night the NBA went dark, 'senior night' and his D.C. roots. Retrieved from https://www.washingtontimes.com/news/2020/apr/ 2/scott-van-pelt-talks-sportscenter-senior-night-cam/ 